Case Reports in
Gastroenterology
Case Rep Gastroenterol 2021;15:70-79

DOI: $10.1159 / 000511137$

Published online: January 25, 2021

(c) 2021 The Author(s)

$\begin{array}{ll}\text { (c) } 2021 \text { The Author(s) } & \text { OPEN } \\ \text { Published by S. Karger AG, Basel }\end{array}$

This article is licensed under the Creative Commons Attribution-NonCommercial 4.0 International License (CC BY-NC) (http://www.karger.com/Services/OpenAccessLicense). Usage and distribution for commercial purposes requires written permission.

\title{
Blastic Mantle Cell Lymphoma of the Gastroesophageal Junction: A Unique Presentation and Literature Review
}

\author{
Ahmed M. Ahmed ${ }^{a} \quad$ Sima Vossough ${ }^{b}$ \\ aDepartment of Medicine, Rutgers New Jersey Medical School, Newark, NJ, USA; \\ ${ }^{b}$ Gastroenterology and Hepatology, U.S. Department of Veterans Affairs, East \\ Orange, NJ, USA
}

\section{Keywords}

Mantle cell lymphoma · Gastroesophageal junction · Immunohistochemistry · Endoscopy

\begin{abstract}
Although vast, the medical literature is deficient in reports of gastroesophageal junction (GEJ) involvement of mantle cell lymphoma (MCL). We present the unique case of a 76 -year-old male who presented with worsening dysphagia, weight loss, and heartburn and who was found to have blastic variant of $M C L$ in the GEJ. He had undergone extensive workup in the past for an ulcerative, gastric/GEJ lesion, found on four separate esophagogastroduodenoscopies (EGDs) and two esophageal ultrasounds, whose biopsies were repeatedly negative for malignancy. On admission, physical examination and labs were unremarkable, but computed tomography showed an irregular mass involving the GEJ. EGD on admission showed a large friable, ulcerated lesion with heaped-up margins involving the GEJ whose biopsies showed histological and immunohistochemical (IHC) findings consistent with blastic MCL. A bone marrow biopsy showed minimal involvement $(<5 \%)$ of $C D 5+/ C D 23+B$ cells and was negative for both cyclin $\mathrm{D} 1$ and $\mathrm{t}(11 ; 14)$. The biopsy of the lesion was diffusely infiltrated by atypical lymphocytes with prominent nucleoli and IHC stains positive for CD20, cyclin D1, BCL-2, and BCL-6 as well as a Ki-67 proliferative index $>90 \%$, all consistent with blastic $M C L$, a rare and aggressive subtype of MCL. He was started on guideline-based chemoimmunotherapy as he was not a
\end{abstract}




\section{Case Reports in Gastroenterology}

Case Rep Gastroenterol 2021;15:70-79 DOI: $10.1159 / 000511137$

(c) 2021 The Author(s). Published by S. Karger AG, Basel www.karger.com/crg

Ahmed and Vossough: Blastic Mantle Cell Lymphoma of the Gastroesophageal Junction

candidate for stem cell transplantation. Repeat imaging 1 year later showed improvement of the mass, with negative endoscopic biopsies for lymphoma. This case provides additional distinct features to the various clinical presentations associated with this rare proliferative disorder, thereby enhancing the medical literature on MCL.

(c) 2021 The Author(s)

Published by S. Karger AG, Basel

\section{Introduction}

Mantle cell lymphoma (MCL) is a rare subtype of B-cell non-Hodgkin lymphoma with an incidence of only $1-2$ cases/100,000 people/year $[1,2]$. It is usually diagnosed at a late stage, with elderly Caucasian males having the highest risk of disease [3-5]. Studies have classified MCL into four main subtypes: classic MCL, small-cell MCL, pleomorphic MCL, and blastic MCL, the latter being the rarest. Moreover, blastic MCL tends to be associated with an aggressive clinical presentation [6]. Diagnosis of MCL is done by histological and immunohistochemical (IHC) analysis of a tissue biopsy, with strong associations to features such as the translocation of $\mathrm{t}(11 ; 14)$ and cyclin D1 overexpression [7]. MCL commonly presents in sites such as lymph nodes, the spleen, or bone marrow, with gastrointestinal (GI) tract involvement, specifically the esophagus, being an unusually rare site [8].

We hereby present the unique case of a 76-year-old male who was found to have a blastic variant of MCL in the gastroesophageal junction (GEJ). This case provides additional distinct features to the various clinical presentations associated with this rare lymphoproliferative disorder, thereby enhancing the medical literature on MCL [9].

\section{Case Report}

A 76-year-old Caucasian male with a history notable for prostate cancer status post brachytherapy and external beam radiation therapy, bladder cancer status post transurethral resection of bladder tumor and bacillus Calmette-Guérin, coronary artery disease, tobacco use (30 pack-years), and gastroesophageal reflux disease presented with 6 months of worsening solid food dysphagia and heartburn symptoms. He described that solid food would get stuck in the substernal region of his chest and was only relieved if he either burped or consumed fluids. After consuming food, he would occasionally feel a nonspecific abdominal pain that resolved over 2-3 h on its own. He was using a proton pump inhibitor daily for his heartburn which generally helped; however, he felt that his reflux was increasing in frequency after meals. He also complained of occasional dark stools over the past month, worsening early satiety, and loss of appetite with subsequent subjective weight loss of approximately 15 pounds over a 2-month time frame. He denied any hematochezia, nausea, vomiting, changes to his bowel habits, recent use of nonsteroidal anti-inflammatory drugs, or use of blood thinners aside from aspirin.

The patient was found to be hemodynamically stable, with a relatively unremarkable physical examination. He had no signs of lymphadenopathy (LAP), hepatosplenomegaly, or abdominal tenderness. Labs were unremarkable except for iron deficiency anemia with a hemoglobin level of $9 \mathrm{~g} / \mathrm{dL}$, an iron level of $13 \mu \mathrm{g} / \mathrm{L}$, and a ferritin level of $10 \mathrm{ng} / \mathrm{dL}$. During his hospitalization, the patient had a computed tomography (CT) scan of the abdomen and pelvis which showed an irregular, lobular mass extending from the GEJ into the proximal fundus of

\section{Karger'=}




\section{Case Reports in Gastroenterology}

Case Rep Gastroenterol 2021;15:70-79 DOI: $10.1159 / 000511137$

c) 2021 The Author(s). Published by S. Karger AG, Basel www.karger.com/crg

Ahmed and Vossough: Blastic Mantle Cell Lymphoma of the Gastroesophageal Junction

the stomach, as well as diffuse LAP involving the celiac axis, iliac chain, and retroperitoneally, along the para-aortic chain.

Of note, the patient reported that he had had several esophagogastroduodenoscopies (EGDs) at a private clinic, with his first one being done 1 year prior to admission. On that EGD, he was noted to have a medium-sized, ulcerated mass with no signs of bleeding in the gastric cardia within a few centimeters from the GEJ whose biopsies showed mild gastritis and areas of intestinal metaplasia. A colonoscopy was also done at that time and was benign except for internal hemorrhoids. A few months later he underwent his second EGD as well as an esophageal ultrasound (EUS), which showed a cratered 7-mm ulceration in the proximal cardia with a hypoechoic, necrotic submucosal lesion having a cystic component. Fine needle aspiration and biopsies were reflexively done, but the pathology results were negative for any evidence of malignancy. A couple of months later, repeat EGD and EUS showed similar findings of a large ulcer within $1 \mathrm{~cm}$ of the GEJ and a hypoechoic mass-like lesion confined to the serosa with no evidence of LAP. Biopsy results were again negative for malignancy. Two months later, repeat EGD and EUS were done and this time showed some improvement in the ulcer's external appearance; however, new wall thickening of the distal esophagus and proximal cardia as well as a similar hypoechoic lesion near the ulcer were discovered. Yet again, fine needle aspiration and biopsies were negative for any malignant cells.

EGD done during his hospital admission showed a large friable, ulcerated lesion with heaped-up margins involving the mucosa of the GEJ circumferentially with extension into the cardia (Fig. 1). Biopsy of the esophagus, GEJ, and cardia showed histological and IHC findings consistent with MCL with features of a blastic variant. Specifically, the GEJ mucosa was diffusely infiltrated by a population of atypical lymphocytes with prominent nucleoli with IHC staining showing lymphocytes positive for CD20, PAX-5, cyclin D1, BCL-2, BCL-6, and a Ki-67 proliferative index $>90 \%$ (Fig. 2). Consequent to the EGD pathology results, a full malignancy workup was done, including a positron emission tomography (PET) scan and a bone marrow biopsy. His PET scan demonstrated similar findings including a large, intensely fluorodeoxyglucose-avid mass involving the distal esophagus and proximal stomach as well as fluorodeoxyglucose-avid LAP involving sites like the gastrohepatic and para-aortic chain, which was consistent with regional metastasis. His bone marrow biopsy result was negative as it showed minimal involvement $(<5 \%$ of total cellularity) of CD5+/CD23+ B cells that were negative for both cyclin D1 and the t $(11 ; 14)$ translocation.

The patient was eventually initiated on an R-CHOP chemotherapy regimen (rituximab, cyclophosphamide, hydroxydaunomycin, Oncovin [vincristine], prednisone). He completed five cycles of R-CHOP and was placed on a rituximab maintenance therapy regimen. He demonstrated good response as his posttreatment PET/CT scan showed resolution of the mass at the GEJ and a decrease in size of the hilar, mediastinal, and retroperitoneal LAP. After R-CHOP induction, a repeat EGD with biopsies showed mild chronic inflammation with reactive and regenerative glandular atypia, but was negative for any lymphoma at the GEJ (Fig. 3). Additionally, the gastric body had IM, but again no dysplasia or lymphoma was evident. The patient has been closely following up at outpatient clinics for continued surveillance of his cancers and has been free of MCL progression for over 2 years.

\section{Karger'=}




\section{Case Reports in Gastroenterology}

Case Rep Gastroenterol 2021;15:70-79

DOI: 10.1159/000511137

(c) 2021 The Author(s). Published by S. Karger AG, Basel www.karger.com/crg

Ahmed and Vossough: Blastic Mantle Cell Lymphoma of the Gastroesophageal Junction

\section{Discussion}

MCL is a rare subtype of B-cell non-Hodgkin lymphoma, accounting for approximately $3-10 \%$ of all non-Hodgkin lymphomas [1]. It has an incidence of approximately of 1-2 cases $/ 100,000$ people/year [2]. MCL is known to predominately affect middle-aged males, with the mean age reported to be around 63 years [3]. More specifically, Caucasian males appear to have the highest risk, with one study showing 91\% of MCL cases to be ethnically white, $4 \%$ black, and around 4\% of Asian/Pacific Islander descent [4]. Most people are diagnosed at a later stage (III-IV), with one study reporting an approximate likelihood of 75\% [5].

A large European study by Tiemann et al. [6] analyzed MCL cases and classified it into four main subtypes based on histological properties. The first subtype is considered the classic MCL subtype and is defined as small to medium-sized, monotonous cells with scant cytoplasm, indented nuclei, and moderately displaced chromatin and can occur in $87.5 \%$ of cases. Smallcell MCL ( $3.6 \%$ of cases) is characterized by small cells with round or slightly indented nuclei and dense chromatin and can be histologically similar to chronic lymphocytic leukemia/small lymphocytic lymphoma. Pleomorphic MCL (5.9\% of cases) has medium to large cells with a moderate amount of cytoplasm, variable-sized nuclei, and pale nuclear chromatin, often mirroring diffuse large B-cell lymphoma. Blastic MCL (2.6\% of cases) was defined as monomorphic sheets of small to medium-sized blasts with fine dispersed chromatin, scant cytoplasm, and frequent apoptotic bodies, mimicking lymphoblastic lymphoma. Of the subtypes, those with blastic features displayed the highest mitotic and Ki-67 index patterns. A high proliferation rate by mitotic or Ki-67 indices was associated with the shorter overall survival. Not surprisingly, other studies have described blastic MCL as having a more aggressive clinical presentation [10-12]. In one series of 52 MCL patients, blastoid transformation occurred in $18(35 \%)$, and in those, the median survival was only 4 months [13]. In the present case, the patient's EGD biopsies illustrated diffuse infiltration of small-sized, atypical lymphocytes with scant cytoplasm and prominent nucleoli, with a Ki-67 proliferative index $>90 \%$, all of which were consistent with the rare, aggressive subtype of blastic MCL.

Diagnosis revolves around tissue biopsy and IHC analysis. Genetic features have been a key factor for the diagnosis and differentiation of MCL from other small B-cell lymphomas. Overexpression of cyclin D1 in MCL is strongly associated with $\mathrm{t}(11 ; 14)$ (q13;q32), which is a translocation that involves the immunoglobulin heavy-chain (IGH) locus on chromosome 14 and the cyclin D1 locus (CCND1) on chromosome 11. It is the molecular consequence of such a translocation that leads to the dysregulated expression of CCND1, which encodes cyclin D, a protein that is not normally expressed in lymphoid cells and is involved in the regulation of the G1 phase of the cell cycle $[7,10]$. Furthermore, the BCL-2 family of proteins is part of a crucial regulatory cascade that is involved in the intrinsic pathway of mitochondrial apoptosis and is known to be a key factor in the pathophysiology of B-cell lymphomas. Chromosome 18q21 amplification has been shown to lead to high BCL-2 protein levels and is observed in a subset of patients with MCL and other non-Hodgkin lymphomas [14]. On the other hand, MCL is usually a BCL-6-negative lymphoma; however, it has been found to be positive in MCL cases with high Ki-67 indices and of the blastic subtype [15]. Moreover, MCL cells are known to express pan-B cell antigens, such as CD19 and CD20, as well as CD5, with one study showing 91\% of cases expressing CD19+/CD5+ cells [16]. In rare cases that do not express cyclin D1, SOX11, a member of the sex-determining region Y-related high-mobility group family of transcription factors, has been shown to be a key marker [17, 18]. Additionally, in MCL cases of diffuse GI tract, presenting as multiple lymphomatous polyposis (MLP), tumor cells have been

\section{Karger'=}




\section{Case Reports in Gastroenterology}

Case Rep Gastroenterol 2021;15:70-79

DOI: 10.1159/000511137

(c) 2021 The Author(s). Published by S. Karger AG, Basel www.karger.com/crg

Ahmed and Vossough: Blastic Mantle Cell Lymphoma of the Gastroesophageal Junction

shown to express the adhesion molecule alpha-4/beta-7 integrin (CD49d), which normally functions as a lymphocyte-attracting signal to the high endothelial venules in the gut-associated lymphoid tissues [19]. In the present case, it is unclear why previous biopsy results were negative for any malignancy, but poor biopsy technique and random biopsy error may have been contributing factors. However, IHC staining of the GEJ/stomach biopsies done at the most recent presentation showed lymphocytes positive for CD20, cyclin D1, BCL-2, and BCL6, which is consistent with the literature for a diagnosis of blastic MCL.

Patients with MCL, including GI involvement, have variable symptom presentations ranging from no symptoms to B symptoms (fatigue, weight loss, night sweats), abdominal pain, melena, or hematochezia. Romaguera et al. [2] reported that in MCL patients, up to 26\% initially present with GI symptoms. In general, the GI tract is the most common extranodal site affected by lymphomas, accounting for up to $20 \%$ of cases [20]. Of the various sections of the GI tract, esophageal lymphomas are the most uncommon location, with one literature review finding only 16 cases of primary esophageal lymphoma, none of which was a case of MCL [21]. Close to $75 \%$ of patients with MCL present with LAP initially, and the remaining individuals present with common extranodal sites, including the spleen (45-60\%), bone marrow ( $>60 \%)$, blood (13-77\%), or Waldeyer's rings [8]. Although extranodal MCL can be localized anywhere in the GI tract, the most common sites are the ileocecal region (35.7\%), the ileum (20.3\%), the rectum (9.1\%), and the duodenum (7.7\%) [22]. In comparison, another clinicopathologic, prospective study of 31 cases of GI involvement discovered the following sites to be involved: stomach (57\%), duodenum (52\%), jejunum/ileum (87\%), colon (90\%), and rectum (69\%) [23]. Like other lymphomas, esophageal involvement of MCL is also extremely rare, with a retrospective study of 35 MCL patients demonstrating esophageal involvement in only 2 cases (5.7\%) [24]. Staging is based on the Ann Arbor classification system with several prognostic indices including the International Prognostic Index and the Mantle Cell Lymphoma International Prognostic Index, with the Mantle Cell Lymphoma International Prognostic Index demonstrating superior predictions in survival after first-line chemotherapy and autologous stem cell transplantation (ASCT) compared to the International Prognostic Index [22, 25]. Moreover, assessment of the Ki-67 proliferative antigen has been an important tool to assess cellular proliferation and is sometimes considered the key biological risk assessor in MCL [22].

The endoscopic characteristics of MCL vary and can occur as erosions, heterogenous ulcers, nodules, fold thickening, protruding masses, or as multiple polypoid lesions. Romaguera et al. [2] illustrated histological evidence of MCL in $88 \%$ of patients in the lower GI tract and $43 \%$ in the upper tract. The study also described endoscopic findings of both upper and lower GI tracts to be normal mucosa (38-51\%), inflammation (2-19\%), nodules/polyps (26-43\%), ulcers (1-9\%), thickening (2-5\%), and masses (0-3\%) [2, 8]. A presentation of MCL known as MLP is a rare entity characterized by the existence of several small nodular or polypoid lesions involving several GI tract segments. Although MLP is highly associated with MCL, other tumors present as MLP and multiple histological types of lymphoma can concurrently be present in MLP [22]. To the best of our knowledge, in non-MLP esophageal presentations of MCL, only 1 case had documented GEJ involvement described as a protruding tumor, but had no indication of having a blastic variant of MCL. The present case, on the other hand, had clear blastic-variant MCL and was discovered endoscopically as a large friable, ulcerated lesion with heaped-up margins at the GEJ, illustrating the unique aspect of this case.

The exact mechanism by which MCL occurs in the GI tract is still unknown. However, studies have hypothesized that the adhesion molecule CD49d plays a role, especially since it functions as a lymphocyte-attracting signal to the high endothelial venules in the gut-associated

\section{Karger'=}




\section{Case Reports in Gastroenterology}

Case Rep Gastroenterol 2021;15:70-79

DOI: $10.1159 / 000511137$

(c) 2021 The Author(s). Published by S. Karger AG, Basel www.karger.com/crg

Ahmed and Vossough: Blastic Mantle Cell Lymphoma of the Gastroesophageal Junction

lymphoid tissues and can be found in cases of diffuse GI tract involvement such as MLP [2, 19]. Another possible mechanism revolves around the idea that MCL originates from naïve B cells in the mantle zones of lymphoid follicles in GI tract lymphoid tissue [2, 8]. Both theories are representative of the current data of MCL cases, specifically when it comes to the esophagus. The esophagus is considered a rare site for MCL and may be a consequence of its relatively low number of lymphoid cells.

Current treatment guidelines for MCL revolve around chemotherapy plus immunotherapy and depend on many factors including patient characteristics, symptoms, and disease stage. Surgical therapies are usually limited to select cases involving uncontrollable bleeding due to extensive polyposis or cases of bowel obstruction [8]. Similarly, radiation therapy may be considered for palliative purposes or in combination with conventional chemoimmunotherapy in select cases. One study showed that use of radiation therapy in 43 patients $(3.6 \%$ of total patients with all stages) with stage I/II disease resulted in an estimated overall survival at 3 years of 93\% [26]. There are several chemoimmunotherapy regimens such as the following: the conventional regimen of bendamustine/rituximab or R-CHOP followed by maintenance rituximab, conventional chemoimmunotherapy followed by ASCT, and intensive chemoimmunotherapy regimens such as R-hyper-CVAD (rituximab, hyperfractionated cyclophosphamide, vincristine, Adriamycin [doxorubicin], dexamethasone)/cytarabine/methotrexate. The exact treatment regimen varies from case to case, but young patients ( $<60$ years) with good performance status, usually measured by the Eastern Cooperative Oncology Group scale (i.e., ECOG score <2), are candidates for induction with conventional chemoimmunotherapy (preferably bendamustine/rituximab) and treatment with either hyper-CVAD alone or conventional chemoimmunotherapy followed by ASCT and subsequent rituximab maintenance $[27,28]$. In general, for elderly patients who are ineligible for ASCT, conventional immunochemotherapy with either bendamustine/rituximab or R-CHOP induction is recommended, with bendamustine/rituximab being the preferred regimen due to its lower toxicity $[22,27]$. Additionally, hyper-CVAD should be used with caution as it is well known to cause more toxic side effects in comparison to other regimens [29].

For the present case, the patient was not a candidate for ASCT due to his age and comorbidities, and consequently the preferred regimen for him was conventional immunochemotherapy. He received five cycles of induction R-CHOP followed by a rituximab maintenance schedule with good response and has been progression-free since his completed induction.

Although rare, a diagnosis of MCL often requires an interdisciplinary approach. There are published reports on the various presentations of MCL as well as a classification system for the disease. It is important to know the type of MCL, such as blastic MCL, as it can change management based on its known association of being aggressive with a high mitotic and Ki-67 index. The present case was notable for IHC staining of the GEJ/stomach biopsies showing lymphocytes positive for CD20, cyclin D1, BCL-2, and BCL-6, which was consistent with the literature for a diagnosis of blastic MCL. Moreover, the patient's EGD biopsies portrayed diffuse infiltration of small-sized, atypical lymphocytes with scant cytoplasm and prominent nucleoli, with a Ki-67 proliferative index $>90 \%$, all of which were consistent with the rare, aggressive subtype, blastic MCL. The esophagus is a known rare location for MCL, but unlike previously reported presentations of blastic MCL, this patient had an endoscopy which showed a large friable, ulcerated lesion with heaped-up margins at the GEJ, illustrating the unique aspect of this case. Clinicians should be diligent when it comes to a diagnosis of MCL and become aware of the various presentations associated with the disease. Although there

\section{Karger'=}




\section{Case Reports in Gastroenterology}

\begin{tabular}{l|l}
\hline DOI: $10.1159 / 000511137$ & ( 2021 The Author(s). Published by S. Karger AG, Basel \\
\hline
\end{tabular} www.karger.com/crg

Ahmed and Vossough: Blastic Mantle Cell Lymphoma of the Gastroesophageal Junction

are therapies, early diagnosis, classification, and staging are crucial to the patient's ultimate clinical response.

\section{Statement of Ethics}

This report did not need IRB approval based on Department of Health and Human Services criteria. The subject in this case report provided written informed consent for publication of his case, including publication of images.

\section{Conflict of Interest Statement}

The authors have no conflicts of interest to declare.

\section{Funding Sources}

The authors confirm that they have no funding sources to disclose.

\section{Author Contributions}

A.M. Ahmed contributed to the conception, literature review, drafting, and revision of the article. S. Vossough contributed to the conception and revision of the article.

\section{References}

1 Reyes CV. Mantle-cell lymphoma in Barrett esophagus. Gastroenterol Hepatol (N Y). 2007 May;3(5):392-4.

2 Romaguera JE, Medeiros LJ, Hagemeister FB, Fayad LE, Rodriguez MA, Pro B, et al. Frequency of gastrointestinal involvement and its clinical significance in mantle cell lymphoma. Cancer. 2003 Feb;97(3): 586-91.

3 Nopjaroonsri P, Mankongpaisarnrung C. Mantle cell lymphoma presenting as diffuse esophageal, gastric, and duodenal bulb polyposis. Ann Gastroenterol. 2019 May-Jun;32(3):317.

4 Ambinder AJ, Shenoy PJ, Nastoupil LJ, Flowers CR. Using primary site as a predictor of survival in mantle cell lymphoma. Cancer. 2013 Apr;119(8):1570-7.

5 Zhou Y, Wang H, Fang W, Romaguer JE, Zhang Y, Delasalle KB, et al. Incidence trends of mantle cell lymphoma in the United States between 1992 and 2004. Cancer. 2008 Aug;113(4):791-8.

6 Tiemann M, Schrader C, Klapper W, Dreyling MH, Campo E, Norton A, et al.; European MCL Network. Histopathology, cell proliferation indices and clinical outcome in 304 patients with mantle cell lymphoma (MCL): a clinicopathological study from the European MCL Network. Br J Haematol. 2005 Oct;131(1):29-38.

7 Bertoni F, Zucca E, Cotter FE. Molecular basis of mantle cell lymphoma. Br J Haematol. 2004 Jan;124(2):13040.

8 Ahmed R, Kumar K, Makker J, Niazi M, Balar B. Recurrent Mantle Cell Lymphoma Presenting as Gastrointestinal Bleeding. Case Rep Gastroenterol. 2018 Aug;12(2):379-84.

9 Ahmed A, Vossough S. Blastic Mantle Cell Lymphoma of the Gastroesophageal Junction: A Unique Presentation. In: ACG 2019 Annual Scientific Meeting Abstracts; Proceedings of American College of Gastroenterology. 2019 Oct 29; San Antonio, Texas. https://doi.org/10.14309/01.ajg.0000596800.80988.2c.

10 Campo E, Raffeld M, Jaffe ES. Mantle-cell lymphoma. Semin Hematol. 1999 Apr;36(2):115-27.

11 Decaudin D, Bosq J, Munck JN, Bayle C, Koscielny S, Boudjemaa S, et al. Mantle cell lymphomas: characteristics, natural history and prognostic factors of 45 cases. Leuk Lymphoma. 1997 Aug;26(5-6):53950.

\section{Karger'=}




\section{Case Reports in Gastroenterology}

\begin{tabular}{l|l}
\hline DOI: $10.1159 / 000511137$ & ○ 2021 The Author(s). Published by S. Karger AG, Basel
\end{tabular} www.karger.com/crg

Ahmed and Vossough: Blastic Mantle Cell Lymphoma of the Gastroesophageal Junction

12 Ott G, Kalla J, Ott MM, Schryen B, Katzenberger T, Müller JG, et al. Blastoid variants of mantle cell lymphoma: frequent bcl-1 rearrangements at the major translocation cluster region and tetraploid chromosome clones. Blood. 1997 Feb;89(4):1421-9.

13 Räty R, Franssila K, Jansson SE, Joensuu H, Wartiovaara-Kautto U, Elonen E. Predictive factors for blastoid transformation in the common variant of mantle cell lymphoma. Eur J Cancer. 2003 Feb;39(3):321-9.

14 Davids MS. Targeting BCL-2 in B-cell lymphomas. Blood. 2017 Aug;130(9):1081-8.

15 Camacho FI, García JF, Cigudosa JC, Mollejo M, Algara P, Ruíz-Ballesteros E, et al. Aberrant Bcl6 protein expression in mantle cell lymphoma. Am J Surg Pathol. 2004 Aug;28(8):1051-6.

16 DiRaimondo F, Albitar M, Huh Y, O’Brien S, Montillo M, Tedeschi A, et al. The clinical and diagnostic relevance of CD23 expression in the chronic lymphoproliferative disease. Cancer. 2002 Mar;94(6):1721-30.

17 Mozos A, Royo C, Hartmann E, De Jong D, Baró C, Valera A, et al. S0X11 expression is highly specific for mantle cell lymphoma and identifies the cyclin D1-negative subtype. Haematologica. 2009 Nov;94(11): 1555-62.

18 Navarro A, Clot G, Royo C, Jares P, Hadzidimitriou A, Agathangelidis A, et al. Molecular subsets of mantle cell lymphoma defined by the IGHV mutational status and SOX11 expression have distinct biologic and clinical features. Cancer Res. 2012 0ct;72(20):5307-16.

19 Hashimoto Y, Nakamura N, Kuze T, Ono N, Abe M. Multiple lymphomatous polyposis of the gastrointestinal tract is a heterogenous group that includes mantle cell lymphoma and follicular lymphoma: analysis of somatic mutation of immunoglobulin heavy chain gene variable region. Hum Pathol. 1999 May;30(5):581-7.

20 Freeman C, Berg JW, Cutler SJ. Occurrence and prognosis of extranodal lymphomas. Cancer. 1972 Jan;29(1): 252-60.

21 Hosaka S, Nakamura N, Akamatsu T, Fujisawa T, Ogiwara Y, Kiyosawa K, et al. A case of primary low grade mucosa associated lymphoid tissue (MALT) lymphoma of the oesophagus. Gut. 2002 Aug;51(2):281-4.

22 Martins C, Teixeira C, Gamito É, Oliveira AP. Mantle cell lymphoma presenting as multiple lymphomatous polyposis of the gastrointestinal tract. Rev Bras Hematol Hemoter. 2017 Jan-Mar;39(1):73-6.

23 Ruskoné-Fourmestraux A, Delmer A, Lavergne A, Molina T, Brousse N, Audouin J, et al.; Groupe D'étude des Lymphomes Digestifs. Multiple lymphomatous polyposis of the gastrointestinal tract: prospective clinicopathologic study of 31 cases. Gastroenterology. 1997 Jan;112(1):7-16.

24 Iwamuro M, Okada H, Kawahara Y, Shinagawa K, Morito T, Yoshino T, et al. Endoscopic features and prognoses of mantle cell lymphoma with gastrointestinal involvement. World J Gastroenterol. 2010 Oct; 16(37):4661-9.

25 Geisler CH, Kolstad A, Laurell A, Räty R, Jerkeman M, Eriksson M, et al.; Nordic Lymphoma Group. The Mantle Cell Lymphoma International Prognostic Index (MIPI) is superior to the International Prognostic Index (IPI) in predicting survival following intensive first-line immunochemotherapy and autologous stem cell transplantation (ASCT). Blood. 2010 Feb;115(8):1530-3.

26 Abrahamsson A, Albertsson-Lindblad A, Brown PN, Baumgartner-Wennerholm S, Pedersen LM, D’Amore F, et al. Real world data on primary treatment for mantle cell lymphoma: a Nordic Lymphoma Group observational study. Blood. 2014 Aug;124(8):1288-95.

27 Rummel MJ, Niederle N, Maschmeyer G, Banat GA, von Grünhagen U, Losem C, et al.; Study group indolent Lymphomas (StiL). Bendamustine plus rituximab versus CHOP plus rituximab as first-line treatment for patients with indolent and mantle-cell lymphomas: an open-label, multicentre, randomised, phase 3 noninferiority trial. Lancet. $2013 \mathrm{Apr}$;381(9873):1203-10.

28 Bernstein SH, Epner E, Unger JM, Leblanc M, Cebula E, Burack R, et al. A phase II multicenter trial of hyperCVAD MTX/Ara-C and rituximab in patients with previously untreated mantle cell lymphoma; SWOG 0213. Ann Oncol. 2013 Jun;24(6):1587-93.

29 Merli F, Luminari S, Ilariucci F, Petrini M, Visco C, Ambrosetti A, et al. Rituximab plus HyperCVAD alternating with high dose cytarabine and methotrexate for the initial treatment of patients with mantle cell lymphoma, a multicentre trial from Gruppo Italiano Studio Linfomi. Br J Haematol. 2012 Feb;156(3):346-53.

Abstract was accepted and presented at the American College of Gastroenterology 2019 Annual Scientific Meeting on October 29, 2019 in San Antonio, TX, USA. 


\section{Case Reports in Gastroenterology}

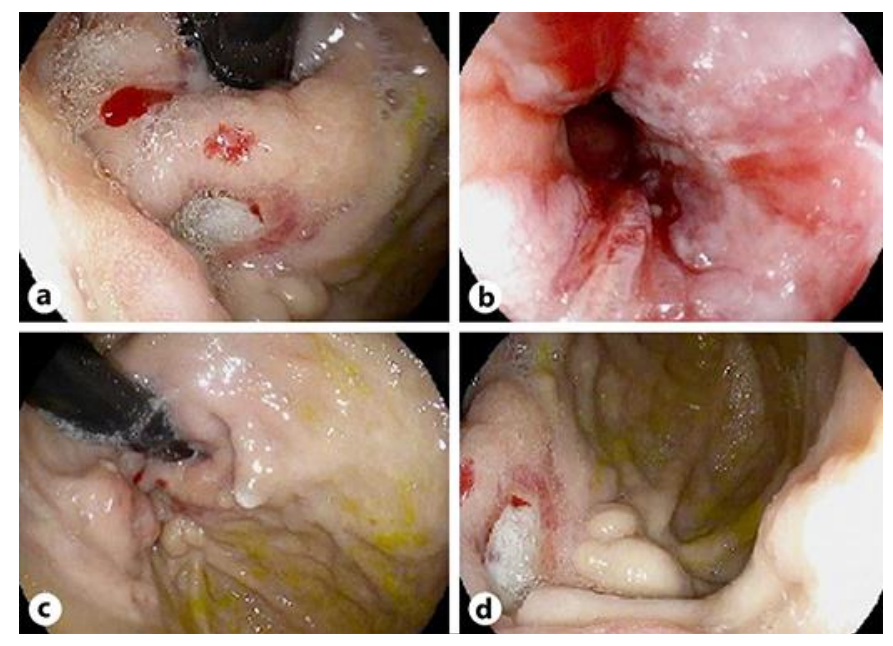

Fig. 1. EGD pictures taken during the patient's hospitalization. a, $\mathbf{d}$ Deep, punched-out ulcer with heapedup margins surrounded by abnormal mucosa. b Infiltrative, friable, circumferential lesion at the GEJ. c Retroflexed view demonstrating a bulging irregularity in the cardia with surrounding abnormal mucosa. EGD, esophagogastroduodenoscopy; GEJ, gastroesophageal junction.
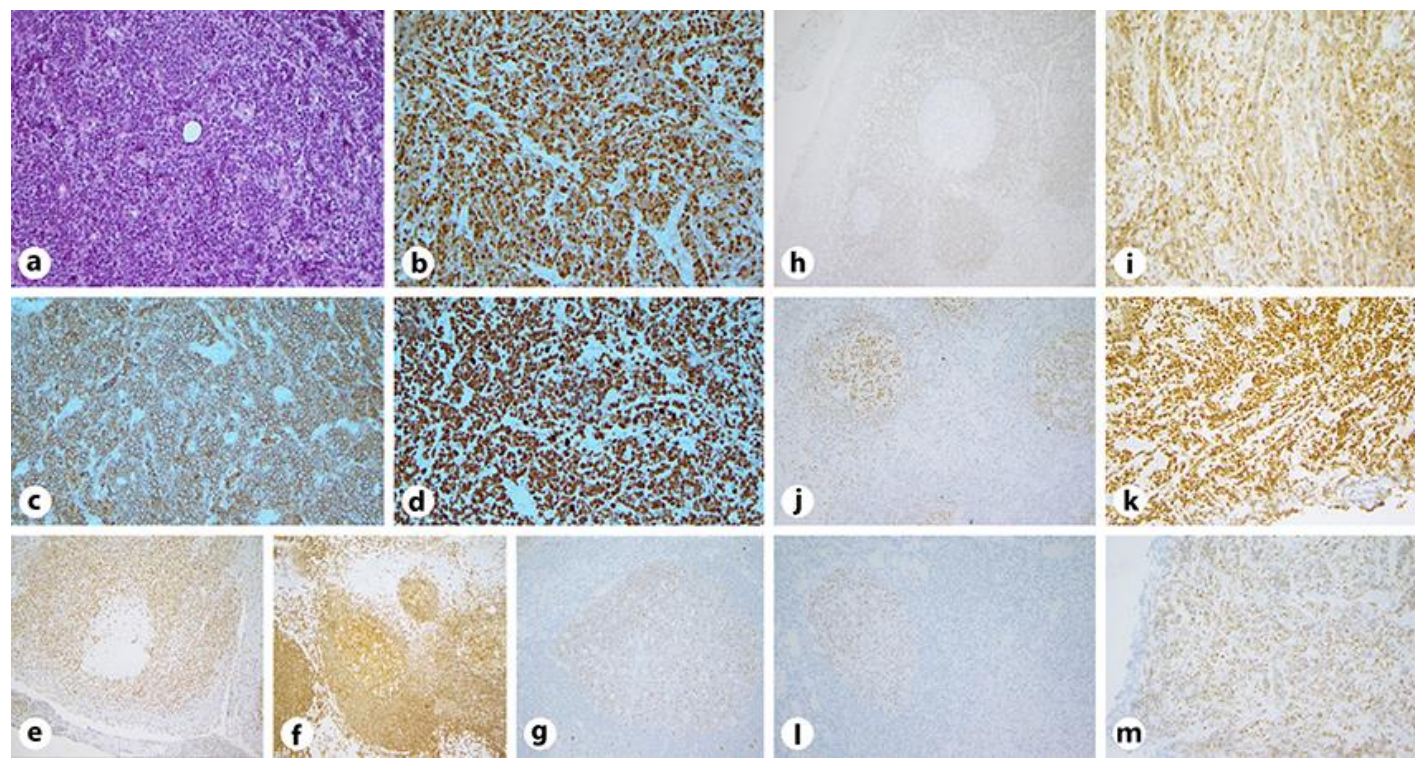

Fig. 2. Histological images from the patient's EGD biopsies of the GEJ and cardia. a H\&E stain $(\times 20)$ demonstrating small-sized, atypical lymphocytes with scant cytoplasm and prominent nucleoli. b, c Key IHC staining patterns (20×): cyclin D1 (b) and CD20 (c). d Ki-67 proliferative index $>90 \%(\times 20)$. e Control for cyclin D1 $(\times 10)$. $\mathbf{f}$ Control for CD20 $(\times 10)$. $\mathbf{g}$ Control for Ki-67 $(\times 10)$. h BCL-2 control $(\times 10)$. i Positive BCL-2 stain from the biopsy $(20 \times)$. j Control for PAX $-5(\times 10)$. $\mathbf{k}$ Positive PAX-5 stain from the biopsy $(\times 20)$. I Control for BCL-6 $(\times 10)$. $m$ Positive BCL-6 stain from the biopsy $(\times 20)$. All IHC stains and histological findings were consistent with blastic MCL. EGD, esophagogastroduodenoscopy; GEJ, gastroesophageal junction; IHC, immunohistochemical; MCL, mantle cell lymphoma.

\section{Karger'}


Case Reports in Gastroenterology (c) 2021 The Author(s). Published by S. Karger AG, Basel www.karger.com/crg

Ahmed and Vossough: Blastic Mantle Cell Lymphoma of the Gastroesophageal Junction

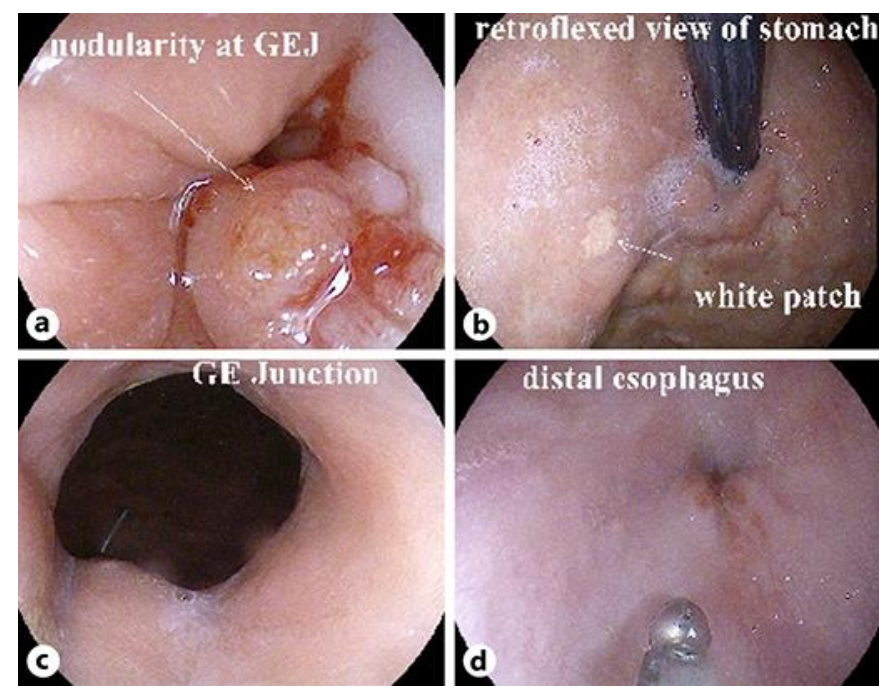

Fig. 3. Images from a follow-up EGD done after five cycles of R-CHOP chemoimmunotherapy. a A nodularity was noticed at the GEJ whose biopsies were later found to be negative for MCL. c, $\mathbf{d}$ The GEJ (c) and distal esophagus (d), which was clearly improved compared to the patient's previous EGD. Moreover, a retroflexed view (b) illustrated resolution of the ulcer and improvement of the surrounding mucosa of the cardia when compared to the previous EGD pictures. EGD, esophagogastroduodenoscopy; GEJ, gastroesophageal junction; MCL, mantle cell lymphoma. 